\title{
A DRAMATURGIA DO TEXTO CURTO
}

\author{
Patrícia Cecato \\ Mestre em Escrita Criativa do Programa de Pós-Graduação em Letras da PUCRS \\ E-mail: patsycecato@gmail.com
}

O formato do texto curto foi proposto em 1842, nos EUA por Edgar Allan Poe e adotado por Anton Tchecov, que acreditava que o tempo era do trem veloz. Assim, o novo formato se constituía a partir de um fato sem interpretação, sem retórica excessiva e com a maior honestidade possível. Produzir um texto curto para teatro requer a consciência de que talvez não seja possível imprimir neles a marca dos grandes personagens. $O$ texto curto descreve primeiro o homem e, então, o seu reflexo de humanidade. Ao se dedicar ao texto curto, o autor tem que estar preparado para fazer opções dentro de limites muito estreitos. A opção mais importante para o desenvolvimento desta estrutura é a escolha do momento a ser capturado entre inúmeros outros, se formos considerar toda a biografia disponível do personagem. É neste curto período de tempo/ narrativa que a história acontece. Esta opção deve estar profundamente conectada com aquilo que é característico, individual e original naquele personagem, alem de apresentar personagens profundamente biográficos. $O$ texto curto para teatro se confunde com o conto literário, no tanto de impacto e no grau de ressonância que causa. Os textos curtos produzidos especialmente para a encenação são aqueles textos escritos para serem ditos por um ator.
The short text format was proposed in 1842 in the USA by Edgar Allan Poe and adopted by Anton Tchekhov, who believed that time was that of the fast train. Thus, the new format was constituted based on a fact without interpretation, without excessive rhetoric and as honest as possible. To produce a short text for theater requires the awareness that perhaps it may not be possible to imprint in them the mark of the great characters. The short text describes firstly the man, and then his reflection of humanity. By devoting to the short text, the author has to be prepared to make choices within very narrow limits. The most important option for the development of this structure is the choice of the moment to be captured among countless other ones, if we consider all available biography of the character. It is in this short time/narrative that the story happens. This option must be deeply connected with what is distinctive, individual and unique in that character, in addition to presenting deeply biographical characters. The short text for theater can be confused with the literature's short story, considering the impact and degree of resonance that both kinds cause. The short texts specially produced for the scene are those written to be spoken by an actor. 


\section{Introdução}

$\mathrm{Na}$ narrativa literária, se quisermos pesquisar sobre a narrativa breve, podemos nos dirigir ao gênero conto. Na narrativa dramática, há uma grande dificuldade em encontrar fontes de pesquisa que englobem a totalidade das premissas do texto curto para teatro. Sendo assim, as reflexões, aqui registradas, foram fragmentadas por áreas de interesse da produção da escrita dramática e, também, o que se costuma designar como a teoria do conto. As áreas investigadas que serviram como substratos da criação artística foram o personagem, a trama, o conflito, a linguagem, a curva dramática, a cena e as possibilidades do encenador. ${ }^{1}$

Pode-se pensar que a pesquisa teórica para esta abordagem se consuma nos estudos sobre o conteúdo do texto, mas acredito que reflexões sobre o ofício do autor também sejam fundamentais para a elaboração interna das motivações que constituíram a obra.

$\mathrm{O}$ ator, dramaturgo, roteirista e diretor de teatro, cinema e televisão, Domingos de Oliveira $(2013$, p. 2), em seu curso de dramaturgia Lições de Liberdade, ressalta que "[...] o autor coloca no mundo algo que não está lá; que o autor sente que, por trás de tudo, tem algo mais; e que o autor está submetido a um pêndulo com alma e, portanto, deve tomar partido".

Goldberg, Campolino e Vieira (2008, p. 48), em Escrevendo com a Alma: liberte o escritor que há em você, acredita que "[...] os escritores acabam, invariavelmente, falando de suas obsessões. Coisas que os assombram, que não conseguem esquecer. Histórias que trazem dentro de si, na esperança de um dia revelá-las ao mundo".

Sobre a história a ser contada, Oliveira (2013, p. 2) diz que se trata de um jogo: "[...] um jogo onde entra o acaso e, no qual, as coincidências se combinam". Ele também aconselha a não desperdiçarmos o material indômito e, sim, exaurir-se do tema no caos. Conforme o conceito desenvolvido pelo dramaturgo:

[...] o material indômito é formado pelos sonhos, fotografias, poesias, filmes, personagens, desenhos, cores, estações, lendas. Após enfrentar o caos, é necessário organizar o material indômito. A boa história é escrita pelo personagem e não pelo autor. $\mathrm{O}$ personagem fascinante é aquele que quebra paradigmas, é aquele que deseja e que nunca está nos lugares pelo motivo que a se acredita que está (Oliveira, 2013 p. 2).

Outro aspecto a ser considerado é a presença do ator, como um dos principais interlocutores do texto para teatro. É ele quem vai vivificar o personagem, mola propulsora da história. Tanto o ator quanto o personagem são ação e reação. Seguindo a definição de Maciel (2003, p. 78), "[...] o ator é aquele ser humano capaz de responder imediatamente ao estímulo imaginário como se fosse real e o personagem sofre estímulos sensoriais e emocionais continuamente deve responder a eles". É nesta via dupla que surgem os personagens convincentes e as grandes interpretações.

Pode-se ir além da compreensão desta ligação estreita entre ator e personagem. Pode-se dizer o personagem não existe, quem existe é o ator que tenta compreender este

\footnotetext{
${ }^{1}$ A pesquisa referida foi realizada no Curso de Mestrado em Letras, no Programa de Pós-graduação em Letras Pontifícia Universidade Católica do Rio Grande do Sul, sob orientação do Prof. Dr.Antonio Hohlfeldt, a qual resultou na dissertação Não se mata pintassilgo e outros textos curtos para teatro.
} 
outro através da imaginação. Portanto, toda a atenção deve ser dirigida à construção de um texto que, diferente da escrita literária, produzida para ser lida, deve ser produzido para ser dito. É através desta conexão entre autor e ator que os textos produzidos para esta obra foram pensados.

Outra definição a ser considerada é a da verossimilhança, que vale para qualquer uma das narrativas, mas que, no texto curto, precisa estar resolvida para evitar qualquer acidente de leitura que possa prejudicar as conexões internas necessárias à compreensão da cena.

O verossimilhante caracteriza uma ação que seja logicamente possível, levando-se em consideração o encadeamento lógico dos motivos, portanto, necessário como lógica interna da fábula. [...] Para a dramaturgia clássica, a verossimilhança é aquilo que, nas ações, personagens, representações, parece verdadeiro para o público $(\mathrm{Pa}$ vis, 1999 apud Pallottini, 2013 p. 35).

Verossimilhança tem algo de verdade; não daquela verdade absoluta, mas, de uma verdade possível de ser compartilhada por todos os envolvidos. Um jogo coerente depende de não só compreensão das regras, como da aceitação delas dentro das possibilidades propostas.

Quanto ao conflito, objeto de tantas considerações dentro do estudo das narrativas, volto a me debruçar sobre a sabedoria de Oliveira $(2013$, p. 3), que defende ser o conflito é um elemento desequilibrado num sistema em equilíbrio:

[...] dramaturgia é causa e conseqüência. Não se pode prever quando um homem encontra o outro. Não se pode medir o medo que um tem do outro.
A vontade de se afastar é tão grande quanto a vontade de se aproximar. É difícil o encontro, mas tem que ser tentado.

Por fim, atentando à grande divisão entre os vários gêneros e sub gêneros que compõe o universo da escrita dramatúrgica, às fronteiras entre o gênero da Comédia e o do Drama e, inclusive, os limites do Drama Moderno.

Dramaturgo Ivo Bender, em seu Comédia e Riso uma poética do teatro cômico (1996), observa que a comédia lida com situações, ações e figuras risíveis e provoca, de imediato, a disponibilidade do espectador. Como o gênero lida com as pequenas falhas humanas e os vícios anódinos, pondo as instituições e as sacralidades na berlinda, ela condena os costumes e expõe os seus ridículos. O espectador se vê, pois, a salvo do partilhamento da dor do herói que a tragédia pressupõe. Os defeitos e falhas dos quais a comédia trata são logo identificáveis, e embora os personagens sofram corretivos, nunca levam seu portador à catástrofe.

Por sua vez, o Drama Moderno, conforme expõe Pasta Jr. (Szondi, 2001), é colocado em confronto com a pureza dialógica de seu próprio modelo - na qual se manifesta a centralidade das relações intersubjetivas -, sendo frequentemente rondado pelo solilóquio e pela mudez, pela objetivação e pela reificação.

A escrita moderna interessa-se pelos limites. No que se refere ao épico, os autores acolheram e redescobriram a arte do contador das antigas tradições orais. No que se refere ao dramático, os autores exploraram diálogos que mantinham o espectador sub-informado, fingindo ignorar a sua presença, deixando-Ihe a responsabilidade 
reinventar o seu estatuto ao concederIhe numa parte de invenção do imaginário (Ryngaert, 1992, p. 26).

Estes são os tópicos principais das pesquisas que fundamentaram nossa abordagem acerca dos textos curtos para teatro. Acredito que possamos inserir, nestes limites a que se submete a escrita moderna, o formato do texto curto. Um sinal dos nossos tempos de fragmentação, de velocidade de informações e de capacidade de concentração. De acordo com Charles Kiefer, este formato foi proposto em 1842, nos Estados Unidos por Edgar Allan Poe e adotado por Anton Tchecov, que, acreditava que o novo tempo era do trem veloz. $\mathrm{Na}$ Rússia, este novo formato, podia ser comparado a um texto de repórter, a partir de um fato sem interpretação, sem retórica excessiva e com a maior honestidade possível.

Produzir um texto curto para teatro requer a consciência de que, talvez, não seja possível imprimir nele a marca dos grandes personagens; aqueles que sofrem, ao fim da narrativa, uma grande modificação em comparação ao seu estágio inicial na história. No texto curto, há uma limitação no tempo de narrativa, esse tempo que se faz necessário para desenvolver uma grande mudança de visão de mundo, de comportamento, um outro olhar sobre o preconceito ou a redenção do protagonista, fato que eleva o texto a um sentido maior, menos homem e mais humanidade.

Ao se dedicar ao texto curto, o autor tem que estar preparado para fazer opções dentro de limites muito estreitos. A opção mais importante para o desenvolvimento desta estrutura é a escolha do momento a ser capturado, dentre inúmeros outros, se formos considerar toda a biografia disponível do personagem. É neste curto período de tempo/narrativa que a história acontecerá. Esta opção deve estar profundamente conectada com aquilo que é característico, individual e original, naquele personagem.

Ibsen e Checkhov eram inimigos do individualismo porque eram amigos da individualidade. Por diferentes caminhos, suas obras estavam impregnadas de amor pelo ser individual e parecem ter inventado um novo método de apresentação das personagens que podemos chamar de biográfico. Um personagem tem agora uma biografia atrás dele, e se o dramaturgo não puder expô-la de uma vez só, soltará a informação em parcelas que o leitor ou espectador poderá depois ajustar e reunir. Isso constituiria a mais original característica do novo drama, no que dizia respeito a suas personagens (Bentley, 1967, p. 64).

A circunstância escolhida para a ação deve se prestar à narrativa do maior número de complexidades possíveis. É como se necessitássemos colocar o personagem em uma armadilha, uma vez ali, o resultado será a violência de uma extraordinária intervenção no curso das coisas.

Se não podemos fazer com que o personagem se modifique, temos que mostrar o quão complexo ele é, através de sua relação com o outro, com o mundo. Acredito que o texto curto, por agregar estas características próprias, tenha o poder de transferir o evento de transformação para o público/interlocutor. Ao ser apresentado a um complexo painel informativo em um curto espaço de tempo e ser impactado por isso este interlocutor terá todo o tempo que precisar para elaborar este conteúdo e, aí sim, há uma chance real de o processo de transmutação ocorrer com sucesso. Podese usar como um bom exemplo as pequenas histórias de Tchecov, aquelas que acabamos de ler continuam ressoando em nossa 
consciência, por muito tempo depois da leitura.

Sabe-se hoje, graças às contribuições da fenomenologia, que toda a consciência é consciência de que algo, que o ser humano não é ilha, prisão, essência. Ele se define por seus contatos, pela maneira de compreender o mundo e de se comprometer. Define-se, ainda, pelo estilo de relação que o une a objetos, aos outros seres humanos e a si mesmo. A criação dramatúrgica é mais um desses lugares privilegiados onde se tenta com simplicidade, e até mesmo muita ingenuidade, compreender o outro (Bezerra, 2011, p. 14).

Ao focarmos no ator em relação ao texto curto, encontramos uma possibilidade de acumular energias subjetivas e intensificar o nível de interpretação da cena. O mesmo limite que restringe o autor do texto curto, obrigando-o a condensar os elementos da narrativa, atinge também o ator, exigindo dele uma boa dose de planejamento para montar uma curva dramática interpretativa e estimulando sua imaginação e inteligência, ao definir como conciliar os elementos subjetivos do personagem aos elementos objetivos da ação e da cena para atingir um resultado coerente e bem sucedido.

Há menos espaço para falhas de ritmo, falta de domínio do texto, intervenções pessoais, substituições de linguagem. Apesar de parecer muito leve, fluido, estilístico, rítmico, dado a respirações e liberdades, o texto curto prevê uma estrutura firme e uma construção sólida. $\mathrm{O}$ ator que encarar o texto curto, terá, necessariamente, que usar de todo o seu rigor para enfrentá-lo e compreender que este texto, a ele apresentado, conterá um forte conceito de performance, que, segundo Mostaço (2011, p. 58), "[...] é aquele ponto limite em que não se pode discernir entre mimesis e vida real". É este momento em que o ator tem uma chance única de acertar. Sendo assim, o texto curto é sempre um desafio e uma aventura.

Uma das considerações mais importantes para a proposta desta reflexão foram sobre os aspectos da narrativa. As opções de narrativas determinam os textos, assim como as histórias se apresentam aos seus interlocutores.

O ato de narrar revela a construção
de uma subjetividade no duplo senti-
do desta expressão: a construção da
realidade por um sujeito e, ao mes-
mo tempo, a construção desse sujeito
através da sua narrativa. Uma narrativa
é sempre uma experiência subjetiva,
mas condicionada, todavia, e seu con-
teúdo e forma, às interações anterio-
res do sujeito com a sua coletividade,
e o senso comum. (Bezerra, 2011 apud
Mendes, 2011, p. 17).

É através do como narrar que acontece o fenômeno da construção do texto. Podemos comparar a narrativa ao material de construção do projeto do texto ou à carne e músculos de um corpo. Preenche, através de uma poética, a estrutura nua e fria do pensamento. É sangue e calor que gera uma idéia de realidade. A narrativa é a matéria inanimada que dá vida a uma criatura frankensteiniana e que, quando nascida, entrechoca-se com o seu criador e se impõe, independente. Como matéria viva ela se torna a consciência que compreende uma realidade e produz significações para ela. Narrar uma história, mesmo que comum e cotidiana, é sempre estabelecer conexões entre si e os outros, humanos ou divinos.

Há uma concordância geral quanto ao fato de que um texto para teatro, independente de sua estatura, dimensão ou fôlego, deve ser escrito para ser dito. Esta característica pode ser vista como mais um limite dentro do qual emerge o trabalho do dramaturgo do texto 
curto. Agora, ao se abrir o campo de visão, observa-se que este limite leva o autor à busca de uma forma de transcendência para meIhor se expressar. A arma mais potente a seu dispor é a criatividade. Quando o espaço aberto da horizontalidade se comprime, a tendência é buscar recursos criativos no espaço da verticalidade. Vemos, hoje, no teatro contemporâneo o uso de vários textos não dramáticos que compõem a cena. Podemos pensar que, hoje, tem-se condições de ampliar a idéia de um texto escrito para ser dito, para um texto escrito que possa ser dito por um ator.

É importante ressaltar que o texto dramático pode e deve ter um estilo estético e formal que permita sua leitura como uma grande travessia num prazer de outra ordem. Se o texto literário ficcional passa a integrar as encenações, desde que possa ser dito por um ator, é justo que a literatura dramática alcance a possibilidade de provocar prazer através de sua leitura. As literaturas se encontram, assim, em suas diferenças e passam a contribuir para a criação de formas híbridas da arte de narrar histórias.

Ao refletir sobre o personagem e sua ação dramática no texto curto para teatro, não se encontram diferenças significativas que afastem sua função no texto mais longo. $O$ que se pode dizer, com clareza, é que este personagem precisa, em sua rápida aparição, deixar rastros de sua biografia, e ser substancialmente empático, a ponto de envolver o interlocutor, através de sua ação dramática, num enredo que está preparado para capturar o interesse e a atenção deste interlocutor, como em uma armadilha, sutil, mas firmemente articulada e executada. Esta ação precisa de um estratagema consistente que encontra sua expressão máxima na nitidez de um diálogo claro, dire- to, franco, honesto, mas que, também em si, carrega suas pegadas, dizendo muito mais do parece dizer.

\begin{abstract}
Cada um desses personagens tem de ser fascinante. O que é um personagem fascinante? Personagens fascinantes tem vontades, tem desejos pelos quais lutam. Um personagem fascinante sabe o que quer. $E$ também não é um homem (ou mulher) como o outros, foge do lugar comum. Tem um segredo que não diz pra ninguém. Nunca está nos lugares pelo motivo que a gente acha que está, é sempre por outro. Tem uma trama interna. Um personagem fascinante (isso é uma regra dramatúrgica importante) tem grande variação durante a peça. Ele não acaba a peça da mesma forma que começou, há uma variação interna. Se você quiser escrever um personagem fascinante, siga esta descrição (Oliveira, 2013, p. 4).
\end{abstract}

O texto curto precisa ser ardiloso, precisa se impor além do tempo veloz, além da compreensão única e do significado unânime. Precisa carregar, em si, o paradoxo. E quem carrega em si as contradições e arrasta o interlocutor para o interior de suas vontades e de seus objetivos, é o personagem. Segundo a poética de Hegel (18--?) "[...] a ação dramática do personagem é a ação de quem quer faz, já que o personagem deve responder por todos os atos que pratica, os quais uma vez praticados, tornam-se irreversíveis. O indivíduo dramático recolhe os frutos do próprio ato".

O conflito é ingrediente essencial de qualquer escrita dramática. $O$ desejo que cria o conflito nem sempre é evidente em sua primeira apresentação. Para os propósitos do conflito o não querer é tão forte quanto o querer ativamente.

Percebíamos que essa trama de interesses, desejos, necessidades, delírio - tão complexa que é difícil saber a 
fronteira entre uns e outros - era não só um tecido de conflitos, mas contradições. E que não pareciam oferecer possibilidade de síntese, ou horizonte de superação: apenas choque, e explosões (Mendes, 2011, p. 48).

Embora a maioria dos pensadores e teóricos vejam o conflito como trauma fundador de uma história, daquilo que aconteceu, daquilo que poderia ter acontecido, da crise, do nó, da colisão, do desacordo entre sentimentos, objetivos e atos, alguns deles concordam que uma boa história se faz com um bom personagem. É consenso que a história dramática vem se apoiando num conflito claro que pode ser definido em uma só frase. Hegel (apud Pallottini 2013 p. 23) afirmou que:

[...] a poesia dramática nasce da necessidade humana de ver a ação representada; mas não pacificamente, e sim através de um conflito de circunstâncias, paixões e caracteres, que caminha até o desenlace final. $O$ conflito está sempre na base do todo.

Há autores, entre os quais eu me integro, que acreditam que somente um personagem rico e complexo pode se envolver e nos envolver num conflito tão rico e complexo quanto ele. Hoje, pode-se perceber, que, em muitas experiências teatrais, o grande conflito está imerso num personagem, que a crise se estabelece entre um personagem e ele mesmo, entre o objetivo e o subjetivo, na mesma pessoa.

Pode-se dizer que se trata de um momento onde o olhar está sobre o indivíduo e suas contradições. Vê-se, também, este fenômeno acontecer com uma infinidade de textos em primeira pessoa, na literatura. Em lugar de um movimento coletivo, um movimento social, o que temos vistos são as explosões internas de um personagem; seus movimentos ocorrem para desobstruir passagens e mexer nas posições sociais definidas. De acordo com Cássia Lopes (2011 p. 32):
[...] já não é suficiente unir duas rea- lidades desiguais e pô-las em conta- to para daí resultar a experiência da fronteira. É necessário perceber o mo- mento e as possibilidades de troca, de negociação, de conflito. Interessa, nes- te caso, verificar quais as formas que puderam passar na zona de contato, quais as condições de tensão e de en- contro entre as marcas e os traços de diferentes culturas relacionadas.

Obviamente, o conflito não perde sua estatura dentro do tecido da história contada. Apenas, neste momento, e talvez, mais aparente no texto curto, o conflito tenha uma interdependência considerável com o personagem que age em direção a ele. Embora Hegel considere o conflito como o centro de tudo, ele, em sua genialidade, pode ser citado mesmo quando há um olhar sobre um centro, mas sobre o que está nas bordas, em direção a este centro - no caso o personagem. Pois Hegel (18--? apud Pallottini 2013 p. 23) diz que:

O personagem moderno, enfrenta conflitos que dependem, mais do que qualquer outra coisa, de seu próprio caráter e que estas personagens indecisas e hesitantes são apresentadas como assediadas por duas paixões que se arrastam em direções opostas. São naturezas duplas que não podem alcançar uma individualidade firme e completa.

A partir da constatação de Ryngaert (1996, p. 21) de que "[...] a maior parte do teatro contemporâneo ignora os gêneros, cada vez menos específicos e que passe a abrigar todos os textos passados pelo palco, fossem ou não a ele destinados", a idéia do texto curto, sem determinar seus gêneros, e sem a 
preocupação de serem essencialmente dramáticos parece bastante coerente e inserida em uma atualidade que facilitará o acesso, a compreensão e o emprego prático dos textos.

Embora quase não permita distinguir com clareza um texto de teatro de um outro texto nas práticas modernas da escrita. A superioridade da ação cênica torna caduca a eventual boa vontade de um autor preocupado em prever, à margem das representações, as ações das suas personagens. Podemos dizer que a maneira como seu texto vai ser "operado" deixou de lhe pertencer e que mesmo que se escreva diretamente para o teatro, o que esperamos dele é um "texto", sem outras definições (Ryngaert, 1992 p. 23).

Ao escrever textos curtos para a encenação, precisa-se estar atento ao enredo. Este item fica mais evidente para o interlocutor nos textos dramáticos, porque o enredo é a própria expressão da historia contada.

A matéria-prima do enredo é a vida, mas não a sofrível vida cotidiana em sua banalidade exterior; pelo contrário, os raros clímax das situações extremas da vida ou a existência cotidiana, em suas formas secretas, não inteiramente conscientes. A perspectiva que rejeite essas situações extremas é anti-dramática. $O$ enredo é a ordenação desse material. Acarreta a aplicação de um princípio racional aos caos do irracional (Bentley, 1967 p. 14).

Na maioria das vezes, quando se pergunta qual é a história de uma peça de teatro, de um filme, de um livro, está se querendo saber do que trata o enredo. Diferente do argumento, que se dedica, exclusivamente, a explicar o conflito, o enredo desenvolve as circunstâncias, influências, situações e personagens que dão vida àquele conflito. Também chamado de trama, o enredo se torna interessante à medida que contém em si um tanto de violência, infortúnio e desastre. Bentley (1967, p. 23) diz que: "[...] uma fatia intragável da vida poderá ser servida e engolida como arte. Não é qualquer desvio da realidade da vida o que nos deleita. $O$ fato de imitar é suficiente para converter a dor em prazer".

O enredo é, ao final de tudo, um meio, um caminho que leva, como um rio caudaloso, do centro às margens, impele e arrasta tudo para uma só direção: a resolução do conflito. Este movimento assoberbado de tempos e acontecimentos, da ignorância e da expectativa do saber, do descobrir, é mais que somente um desenvolvimento da história, é uma evolução: "[...] aí onde existe teatro de verdade o homem sempre entrega algum de seus segredos, algum de seus movimentos, alguma de suas glórias, alguma de suas derrotas." (Palant, 1968, p. 14, tradução nossa)².

Se a opção na produção de textos curtos for pelos enredos ou tramas, que girem em torno, principalmente, do homem comum e de suas pequenas intrigas cotidianas - digo pequenas sob a perspectiva dos grandes dramas humanos -, se o foco estiver no microcosmo do drama comum, como uma lente de aumento; as sensações se ampliam além dos seus próprios limites. Dor é dor, emoção é emoção. Para quem as vive e as sente, a dimensão é única, intensa, irreversível. Neste contexto, não há avaliação possível de como a natureza dos fatos implicará em quem os vive e naqueles que assistem ao evento e se identificam com ele. Portanto, nada é pequeno demais ou grande demais; tudo depende da proporção

2 [...] allí donde hay teatro de verdad el hombre entrega siempre alguno de sus secretos, alguno de sus movimientos, alguna de sus glorias, alguna de sus derrotas. (Palant, 1968, p. 14). 
do universo em que se dá a história.

Nos textos curtos não dramáticos, a identificação do enredo é sempre possível, mas nem sempre tão clara e objetiva como nos textos reconhecidamente dramáticos. Com o invólucro construído dentro de uma subjetividade maior, estes enredos estarão à mercê do particular de cada interlocutor e, assim devem estar, e ali devem ser terreno fértil para as concepções próprias.

Podemos pensar, então, que o texto curto pode contemplar, em relação aos enredos e seus relatos, do ordinário e universal ao particular, do olhar objetivo e ostensivo ao subjetivo, de acordo com a feição de cada texto, dentro do arranjo de textos dramáticos e não dramáticos. Ao pensar o texto curto para teatro como instrumento de pesquisa, ensaio e prática de encenação há de se levar em consideração as estruturas da cena, do diálogo, do monólogo e dos mini textos.

Maciel (2003, p. 100) distinguiu a Cena em "[...] lógica, obrigatória, dramática, estrutural, psicológica e histórica." No texto curto, nem sempre conseguiremos acoplar todas estas concepções de cena ao texto, mas há de se tentar agregar combinações que, certamente, Ihe trarão riqueza e força.

Portanto, se uma só cena tem que dar conta de sua finitude, isolamento, independência e do desafio de comportar em si a totalidade da história, elas terão de ser, necessariamente dramáticas, no sentido de enfrentamento, de tensão, de embate.

Um texto dramático composto de uma única cena exige que esta cena tenha uma estrutura, por exemplo, com três atos e em torno de cinco plot points - termo utilizado no roteiro audiovisual que define o pontos de desdobramento da cena - que permita que ela respon- da por si mesma. Essa estrutura é a mesma que se usaria para a escrita de uma experiência dramática contínua. Isto comprova que a cena única tem suas responsabilidades.

Um texto curto composto de uma cena única, bem estruturada, permite ao ator um exercício contínuo para evoluir dentro dela. Cada virada é um desafio. E acontece tão rápido, que, os vários gatilhos das ferramentas de atuação tem de ser ativados um após o outro, ou mesmo, alguns deles ao mesmo tempo. Tudo está em jogo: a inteligência, o ritmo, a sensibilidade, a imaginação, a escuta, o corpo, a voz, a ousadia e a subjetividade. Por isso, um bom planejamento de estrutura da cena, uma construção de síntese do que é fundamental e elipses do que pode ficar subtendido, faz com que a cena curta tenha o desejado poder de intensidade.

Para explanar sobre os textos que compõem o grupo dos Diálogos - cenas com dois personagens ocupados em se desembaraçar de um conflito comum, precisamos, antes, traçar um panorama das teorias instituídas sobre as características e funções do diálogo.

O diálogo é chamado de corpo de comunicação do roteiro, e é usado para caracterizar os personagens, para passar as informações sobre a história e, ainda, para fazer avançar nossa história através do seu escrever. Enfim, um bom diálogo deve estar repleto das emoções dos personagens. O diálogo não é a narrativa lógica dos problemas e informações da história, mas sim, a fala emocionada, a fala que expõe, via emoção, o que acontece com o personagem (Comparato, 1983, p. 159).

Alguns conceitos encaminham a idéia de que a principal função do diálogo é desvendar a emoção de um personagem frente a uma situação. Uma boa fala, enunciada de maneira 
certa pelo ator - este que ilumina as falas com a compreensão própria que tem da vida interior do personagem - exercerá o necessário impacto sobre o público. O personagem, na cena em geral, é bem mais articulado do que o seria na vida real, mas, ainda que consiga criar uma ilusão de realidade, as confusões, os excessos, as hesitações e o vaivém da conversa comum foram podados. Essa intensificação da fala normal constituiria um padrão para o diálogo.

O diálogo registra o que os personagens dizem. O diálogo dramático é a expressão direta da ação. Os personagens não conversam, eles agem! Os diálogos são uma exteriorização da ação, ou, mais exatamente, da interação entre os personagens. Diz-se que o diálogo eficiente tem três funções: faz avançar a história, define os personagens e fornece ainda outras informações necessárias ao espectador (Maciel, 2003, p. 91).

Ao pesquisar sobre as teorias do diálogo, encontramos regras bem definidas. Algumas delas aparecem nas enunciações de diversos autores. A estrutura econômica, orgânica e funcional do diálogo tem gerado regras tão econômicas, orgânicas e funcionais quanto ele.

Howard e Mabley (1996, p. 140), teóricos das técnicas de roteiros, em seu Teoria e Prática do Roteiro ressaltam que "[...] falar é apenas uma parte daquilo que fazemos enquanto seres humanos e que deveria ser também uma pequena parte de como contamos uma história ao público." Aqui eles apontam para a ação que acompanha as palavras. Os textos produzidos como diálogos não estão de todo livre de indicações, que imprimem uma certa concepção intrínseca, porém oferecem muitas outras dimensões para o desenvolvimento das ações, que são os instrumentos das palavras para desenvolver a história.

Outro dado importante, Outro dado importante, na construção de diálogos, que se mostra extremamente importante para o exercício da interpretação, é a visão que deve povoar a fala, as imagens que povoam a imaginação dos envolvidos no jogo da encenação. Nos diálogos, há ação, há imagens, há espaço para o corpo do ator e para a concepção do diretor, mas, antes de tudo, estes diálogos são histórias contada através palavras. Estas são o instrumento para estabelecer o que se busca nestes textos: a relação entre dois, entre o eu e o outro, duas forças contrárias se enfrentando, dois universos em choque. Sobre a poética que envolve o diálogo, vale citar, por fim, Howard e Mabley (1996 p. 140):

[...] o diálogo pode ser a única parte do roteiro que o público vivencia diretamente, é a área onde o roteirista pode expressar e tirar o melhor partido de toda a sua poesia interior. Introdução delicada do humor, cadência, escolha de palavras, ritmo e visões - características, todas elas da poesia.

No grupo dos monólogos que, por definição, indicam os textos em que um indivíduo, no caso um ator, achando-se só fala consigo mesmo ou se dirige ao público, principalmente expressando seus pensamentos, as lutas interiores do seu espírito, encontra-se uma seleção de textos que representa de certa forma a literatura do eu, tão abundante nesta nossa contemporaneidade.

Pode-se entender, ao se analisar essa literatura em primeira pessoa, que vivemos a era do auto-conhecimento, das autobiografias, das viagens memorialísticas, das experiências individuais ou do simples contar fatos do próprio eu, que parecem interessar ao alheio. 
O que se sabe é que há uma intensa necessidade de expor ao mundo aquilo que é particular como visão de mundo, convicções e atitudes.

Muitos dos textos que integram os monólogos, têm características marcantes do texto autobiográfico, o que parece uma opção consistente, porque, embora totalmente ficcionais, esses textos contém uma expressão da verdade e um ar de autenticidade. Podemos sentir, neles, a força da experiência vivida. $\mathrm{E}$ esta é uma característica extremamente bem vinda quando se trata deste tipo de texto para o exercício dramático da interpretação. $O$ ator deseja conquistar um nível poderoso de veracidade, autenticidade e sinceridade, ou deveria desejar.

Ao abordar aqueles pequenos textos que incluem as prosas poéticas, fragmentos de memória, minicontos, é preciso pensar em como incluí-los em determinada categoria ou referência. Seriam textos não dramáticos, seriam textos literários, seriam textos filosóficos? Às vezes eles se enquadram em uma destas categorias e às vezes em algumas destas categorias ao mesmo tempo. Eles contem a qualidade da fusão, de uma certa combinação, de um certo entrelaçamento que torna complexo categorizar qualquer um deles em uma forma pura.

Ao que parece, hoje é impossível definir as características absolutas da escrita teatral, pelo menos em termos teóricos. Os critérios que abordamos permanecem, mesmo assim, úteis para avaliar as evoluções dos textos e situá-los numa perspectiva histórica. O teatro atual aceita todos os textos, quaisquer que sejam as suas origens, e deixa à encenação a responsabilidade de revelar a sua teatralidade e, na maior parte das vezes, ao espectador, descobrir o seu alimento. A escrita tea- tral ganhou em liberdade e em flexibilidade o que por vezes perdeu em identidade (Ryngaert, 1992, p. 29).

Alguns dos pequenos textos são memórias ou lembranças. Eles aparecem como iluminações sobre um tempo curto e específico do passado. Funcionam como uma espécie de insight de uma situação vivida e, naquele momento, compreendida em suas relações.

Outros minitextos se encontram dentro da ordem das prosas poéticas, um gênero um tanto obscuro em suas conformações. Sobre ele, pode-se dizer que expressa um momento, uma atmosfera, um estado da alma frente a um recorte de realidade. Não se espera, nestes textos, encontrar uma ação e, sim, uma moldura para o instante, um flagrante. De todos os textos literários, a prosa poética é a que mais se conecta com a fotografia e com a pintura. Ela é como um quadro feitos de palavras.

Outros, ainda, podem ser considerados nanocontos, os quais não podem ser constituídos como gênero literário, mas talvez se possa considerá-los como uma tendência contemporânea, produto do minimalismo. Nesta estrutura narrativa, o que importa é a essência e as elipses. A essência é a qualidade que desafia o autor a desprezar tudo aquilo que pode ser sobra ou acessório. As elipses transferem ao interlocutor a tarefa de preencher os espaços vazios, os saltos quânticos e entender a história por trás da história contada. Se, no conto, há um equilíbrio ente a história aparente e a história oculta, no nanoconto a ênfase se encontra no lado obscuro da narrativa.

Todos estes breves relatos podem não estar entre as definições do texto dramático, mas compreendem uma função importante dentro dos exercícios de atuação. Exigem uma busca mais ampla na compreensão das suas 
significações, tanto para o ator ao interpretá-lo quanto para o espectador, ao assisti-los. Exigem um mergulho mais profundo no espírito do texto, nas novas coerências que ele propõe e uma liberdade maior nas opções interpretativas. Sempre se mostram como um desafio às possibilidades do ator, além de serem material seleto para testes, audições e registros de atuação.

Referências

BENDER, Ivo C. Comédia e riso: uma poética do teatro cômico. Porto Alegre: Ed Universidade UFRGS/EIPUCRS, 1996.

BENTLEY, Eric. A Experiência do Teatro. Rio de Janeiro: Zahar, 1967.

BEZERRA, Antonia Pereira. Do texto à encenação: a expansão cênica da narrativa e sua eficácia simbólica. In: MENDES, Cleide Furtado. (Org.). Dramaturgia, ainda: Reconfigurações e rasuras. Salvador, EDUFBA, 2011.

COMPARATO, Doc. Roteiro: arte e técnica de escrever para cinema e televisão. Rio de Janeiro: Nórdica, 1983. p.159.

GOLDBERG, Nathalie; CAMPOLINO, Camila Lopes; VIEIRA, Silvana. Escrevendo com a Alma: liberte o escritor que há em você. São Paulo: WMF Martins Fonte, 2008

HOWARD, David. Teoria e prática do roteiro. São Paulo, SP : Globo, [1996?]. 403 p.

LOPES, Cássia. A dramaturgia do futebol: o passe de bola de Gilberto Gil. In: MENDES, Cleide Furtado. (Org.). Dramaturgia, ainda: re- configurações e rasuras. Salvador: EDUFBA, 2011. p. 32.

MACIEL, Luis Carlos. O poder do clímax: fundamentos de roteiro de cinema e tv. Rio de Janeiro: Record, 2003. p. 78.

MENDES, Cleide Furtado. Dramaturgia ainda, aqui e agora. Salvador: EDUFBA, 2011.

MOSTAÇO, Edélcio. A partir de que fileira é possivel iludir o olhar do público?. In: MENDES, Cleide Furtado (Org.). Dramaturgia, ainda: Reconfigurações e rasuras. Salvador, EDUFBA, 2011.

OLIVEIRA, Domingos. Curso de Dramaturgia Lições de Liberdade. Centro Cultural b_arco . São Paulo, 2013. p. 2. (Material didático).

PALANT, Pablo. El Texto Dramático. Buenos Aires: CEAL, 1968. p. 14.

PALLOTTINI, Renata. Dramaturgia: a construção do personagem. São Paulo: Perspectiva, 2013.

PAVIS, Patrice apud PALLOTINI, Renata - Dramaturgia: a construção do personagem - São Paulo - Perspectiva, 2013, p. 35

RYNGAERT, Jean-Pierre. Introdução à análise do teatro. São Paulo: Martins Fontes, 1996.

SZONDI, Peter. Teoria do Drama Moderno (1880-1950). São Paulo: Cosac \& Naify, 2001.

Recebido em 08/12/2015 Aprovado em 12/06/2016 